\title{
CONSTRUÇÃO COLABORATIVA DE UM PLANO DE AÇÃO PARA A EDUCAÇÃO INCLUSIVA: COMO A EXPERIÊNCIA EDUCACIONAL FINLANDESA PODE RECHEAR ESSE PROCESSO?
}

\author{
CONSTRUCCIÓN COLABORATIVA DE UN PLAN DE ACCIÓN PARA LA \\ EDUCACIÓN INCLUSIVA: CÓMO LA EXPERIENCIA EDUCACIONAL \\ FINLANDESA PUEDE RECHAZAR ESTE PROCEDIMIENTO?
}

\section{COLLABORATIVE CONSTRUCTION OF AN ACTION PLAN FOR INCLUSIVE EDUCATION: HOW CAN THE FINNISH EDUCATIONAL EXPERIENCE MAY HELP THIS PROCESS?}

\author{
Renato Aparecido DE SOUZA ${ }^{1}$ \\ Grasiane Cristina da SILVA ${ }^{2}$ \\ Matheus Batista Barboza COIMBRA ${ }^{3}$
}

RESUMO: O presente artigo aborda o uso das metodologias ativas, aprendizagem baseada em projetos e aprendizagem centrada no estudante, as quais se contextualizam com a Educação Finlandesa, em prol da organização e construção de um Plano de Ação acerca da Educação Inclusiva. É apresentada uma rotina pedagógica para um período de quatro horas com uso de estratégias educacionais para a promoção da discussão da Educação Inclusiva. Aproximadamente 160 servidores (professores e técnicos administrativos) do Instituto Federal do Sul de Minas Gerais, campus Muzambinho, desenvolveram um documento oficial com 8 dimensões (Gestão Escolar; Prática pedagógica; Avaliação; Acesso, Permanência e Sucesso na escola; Ambiente educativo; Formação dos profissionais do campus; Relação Escola-Família; e Integração Escola-Trabalho) em uma plataforma digital (Padlet). Ao final, os resultados puderam subsidiar futuras ações institucionais para a Educação Inclusiva. Além disso, perceber mesmo que subjetivamente o olhar de contentamento de grande parte dos servidores em reconhecer que cada um teve papel fundamental no documento implica em acreditar que é possível alterar algumas rotinas educacionais com o uso das bem-sucedidas experiências finlandesas.

PALAVRAS-CHAVE: Sistema educacional finlandês. Metodologias ativas. Educação inclusiva.

RESUMEN: El presente artículo aborda el uso de las metodologías activas, el aprendizaje basado en proyectos y el aprendizaje centrado en el estudiante, que se

1 Instituto Federal de Educação, Ciência e Tecnologia do Sul de Minas Gerais (IFSULDEMINAS), Muzambinho - MG - Brasil. Professor e participante dos programas Professores para o Futuro (VET) e Finish Train the Trainers. E-mail: renato.souza@muz.ifsuldeminas.edu.br

2 Instituto Federal de Educação, Ciência e Tecnologia do Sul de Minas Gerais (IFSULDEMINAS), Muzambinho - MG - Brasil. Membros do Núcleo de Apoio as Pessoas com Necessidades Especiais (NAPNE)

3 Instituto Federal de Educação, Ciência e Tecnologia do Sul de Minas Gerais (IFSULDEMINAS), Muzambinho - MG - Brasil. Membros do Núcleo de Apoio as Pessoas com Necessidades Especiais (NAPNE).

RIAEE - Revista Ibero-Americana de Estudos em Educação, Araraquara, v. 13, n. esp1, p. 576-585, maio 2018. E-ISSN: $1982-5587$. 
contextualizan con la Educación Finlandesa, en pro de la organización y construcción de un Plan de Acción sobre la Educación Inclusiva. Se presenta una rutina pedagógica para un período de cuatro horas con el uso de estrategias educativas para la promoción de la discusión de la Educación Inclusiva. En el caso de los municipios de la ciudad de Buenos Aires, en el marco de la Conferencia de las Naciones Unidas sobre el Cambio Climático, profesionales del campus, Relación escolar - Familia, e Integración Escuela-Trabajo) en una plataforma digital (Padlet). Al final, los resultados pudieron subsidiar futuras acciones institucionales para la Educación Inclusiva. Además, percibir incluso que subjetivamente la mirada de satisfacción de gran parte de los servidores en reconocer que cada uno tuvo un papel fundamental en el documento implica creer que es posible cambiar algunas rutinas educativas con el uso de las exitosas experiencias finlandesas.

PALABRAS CLAVE: Sistema educativo finlandés. Metodologías activas. Educación inclusiva.

ABSTRACT: This article discusses the use of active methodologies, project-based learning and student-centered learning, which is in line with some Finnish Education essential elements, to support the organization and construction of an Action Plan on Inclusive Education. It presents a pedagogical routine for a period of four hours using educational strategies to promote the discussion of Inclusive Education. Approximately 160 civil servants (teachers and administrative technicians) from the Federal Institute of South of Minas Gerais, Muzambinho Campus have developed an official document with 8 dimensions (School Management, Teaching Practice, Evaluation, Accessibility, permanence and success in school, Educational environment; Professional Development; School-Family Relationship; and School-Work Integration) on a digital platform (Padlet). At the end, the results could support future institutional actions for Inclusive Education. Moreover, it was possible to notice, in an empirical way, that most of the collaborators seemed to be satisfied by recognizing that each one had performed a key role in the document construction, which implies considering that it is possible to change some educational routines through the use of some successful Finnish experiences.

KEYWORDS: Finnish educational system. Active methodologies. Inclusive e education.

\section{Introdução}

As reuniões pedagógicas representam um dos grandes desafios de uma Instituição de Ensino. A organização das pautas, dos personagens envolvidos, do material de apoio, dos recursos disponíveis e da estrutura física por vezes é tratada levando em consideração uma rotina tradicional e conveniente da escola. Dessa maneira, o repensar das reuniões pedagógicas no contexto educacional deve ser entendido como um melhoramento para o enfrentar de novos desafios (BRANDÃO, 2005).

O Instituto Federal de Educação, Ciência e Tecnologia do Sul de Minas Gerais (IFSULDEMINAS) instituiu, no ano de 2016, o Dia Escolar, no qual são reunidos todos os 
professores e técnicos administrativos que possuem envolvimento com as questões pedagógicas para debater e elaborar ações em prol de uma determinada questão da Escola. Em 2017, o tema do $2^{\circ}$ Dia Escolar foi a Educação Inclusiva, e cada campus do IFSULDEMINAS teve autonomia para elaborar um plano de ação (PLAC) para essa temática durante um único período vespertino.

Nesse cenário, o Núcleo de Apoio a Pessoas com Necessidades Especiais (NAPNE) do campus Muzambinho resolveu organizar a construção do PLAC levando em consideração o viés das metodologias ativas e da aprendizagem centrada no estudante, as quais se contextualizam com a Educação Finlandesa. Portanto, o desafio estava posto: discutir Educação Inclusiva com aproximadamente 160 servidores (professores e técnicos administrativos) do campus Muzambinho, desenvolver um documento oficial com 8 dimensões, aplicar algumas experiências educacionais Finlandesas e enfrentar um curto período de tempo (quatro horas) para encerrar todas essas questões.

Após três prévias reuniões entre os autores desse relato, foram construídos os seguintes princípios pedagógicos para a construção das rotinas em prol do PLAC (MALLINEN; PROKKI, 2016):

- Aprendizagem baseada em projetos/problemas (ABP);

- Trabalho colaborativo em grupo com atitude dialógica (empoderamento do diálogo entre pares);

- Uso dos mais altos níveis cognitivos (processos de análise, processos de avaliação e, sobretudo, os processos de criação);

- Aprender fazendo;

- Inovação Educacional (oficinas, elementos não tradicionais à sala de aula e uso da tecnologia).

\section{Rotina de Experiência Educacional}

Especificamente para o Dia Escolar, foram definidos e estruturados objetivos de aprendizagem integrados com seis momentos distintos:

1) No período da manhã (uso de pulseiras) (08:00-08:20): à medida que cada servidor chegava na Escola, recebia uma pulseira de identificação (oito cores diferentes), de maneira aleatória e sem nenhuma explicação do que se tratava (Fig. 1). Foram distribuídas 
20 pulseiras de cada uma das cores, totalizando 160 pulseiras. Ressalta-se que nesse período o desenvolvimento do PLAC ainda não poderia ser iniciado, uma vez que todos os servidores estiveram em um auditório assistindo por webconferência uma mesa-redonda sob a temática da Educação Inclusiva.

\section{Objetivos da tarefa:}

- Estímulo à curiosidade;

- Separação de grupos colaborativos aleatoriamente (experiência prévia diversificada);

- Percepção e identificação de pares (introdução à ideia de grupos).

2) Assim que retornam do almoço (13:45-14:00): à medida que cada servidor retornava do almoço, sem nenhum tipo de orientação verbal, eles aos poucos foram identificando visualmente as pulseiras coloridas posicionadas no piso tátil da Escola (Fig. 1), as quais orientavam cada uma das oito cores para oito salas de aula diferentes. Intencionalmente foram separados 20 servidores para cada sala de aula. Cada sala de aula possuía um tutor e dois monitores responsáveis pela condução das rotinas.

Figura 1: Pulseiras coloridas dispostas ao longo do piso tátil da Escola

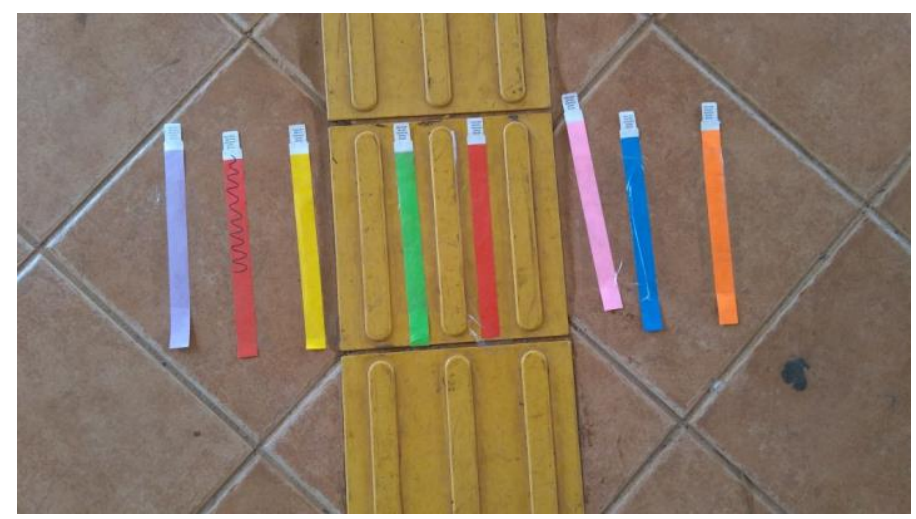

Fonte: Arquivo pessoal

\section{Objetivos da tarefa:}

- Orientação espacial;

- Compreensão de sinais;

- Introdução à ideia da cooperação (eventualmente houve ajuda entre os servidores para a compreensão do que estava acontecendo); 
- Reflexão acerca da deficiência visual.

3) Nó Humano (14:00-14:15) (Warm-up/Breaking Ice): Assim que todos os servidores encontraram suas respectivas salas de aula, o tutor de cada sala de aula iniciava uma dinâmica, separando dois grupos de 10 servidores. Em pé, os servidores de cada grupo deveriam formar um círculo, voltados para o centro, e dar as mãos para dois colegas distintos, formando um "nó humano" (Fig. 2). Feito isso, estava formado o nó Institucional da Educação Inclusiva. Foi então solicitado que os servidores conversassem entre eles e sem soltar as mãos procurassem uma solução para desatar esse nó.

Figura 2: Servidores tentando desfazer o nó, metaforicamente chamado de nó da Educação Inclusiva

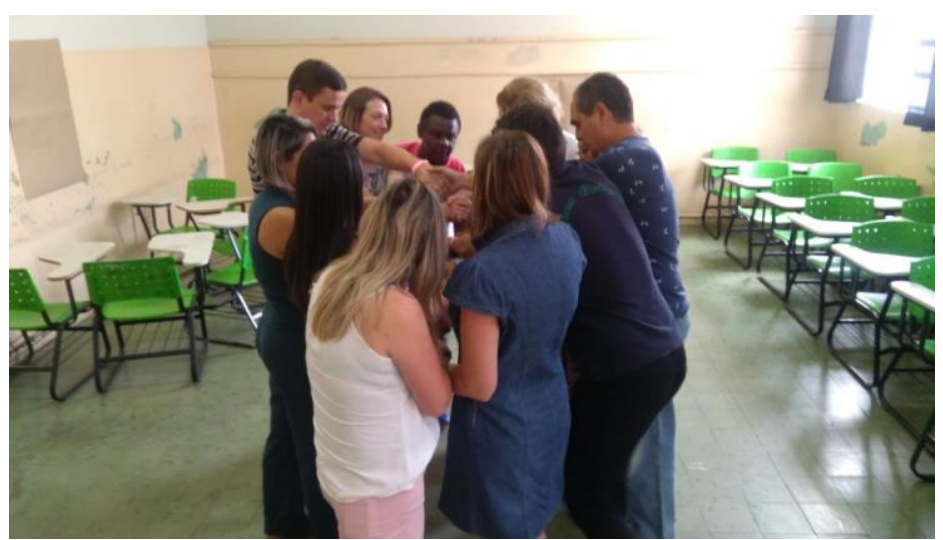

Fonte: Arquivo pessoal

Realizada a dinâmica do nó humano, passou-se para um momento de autorreflexão, onde o tutor da sala de aula fez a leitura do seguinte texto provocativo: "Diante do nó que a Educação Inclusiva causa na escola... 1) Qual tem sido o meu comprometimento em resolver o problema, será que continuo de mãos dadas com os meus colegas e juntos tentamos solucionar, ou estou isolado, sozinho e às vezes de braços cruzados? 2) Qual a importância do apoio, das palavras, das orientações, das sugestões e das correções que meus colegas me fornecem? Estou disposto a receber esses feedbacks e aprimorar minhas ações colaborativamente? 3) Qual a importância das minhas próprias atitudes verbais e atitudinais para resolver esse problema? 4) Estamos nos esforçando o suficiente para resolver o nó da Educação Inclusiva? Será necessário alguma ajuda externa?

\section{Objetivos da tarefa:}


- Exercício de como trabalhar colaborativamentelequipe;

- Reflexões sobre deficiências e habilidades;

- Importância da confiança no processo criativo;

- O poder do discurso e das regras em limitar ou não os processos;

- Encorajamento da persistência;

- Atitudes de Liderança.

4) Metodologia Ativa Jigsaw (14:15-15:30): Feita a autorreflexão, foram separados aleatoriamente 4 grupos colaborativos de 5 servidores, sendo esses direcionados para uma das 4 mesas de trabalho. Cada mesa de trabalho tinha uma questão gatilho em uma folha flipchart, a saber:

- Como desenvolver um projeto pedagógico inclusivo?

- Como formar redes de apoio à Educação Inclusiva?

- Como ajustar o ambiente de aprendizagem (sala de aula e arredores) para favorecer a inclusão?

- Como favorecer a inter-relação dos estudantes com deficiência com aqueles ditos sem deficiência?

Em cada mesa de trabalho, foi decidido aleatoriamente quem seria o líder para sintetizar e registrar as respostas dos colegas (foi utilizado cartas de baralho para o sorteio do líder, quem retirasse a carta "rei" seria o líder). O líder também registrou o tempo das falas e controlou a organização das discussões. Todos os demais servidores de cada mesa de trabalho deveriam responder à questão gatilho, levando em consideração um tempo limitado de fala, que foi de um minuto. Para tanto, o líder distribuía uma cédula com a descrição "vale um minuto". Após a fala de todos os servidores de cada mesa de trabalho, o líder ainda poderia "liberar" mais duas cédulas do "vale um minuto" para dois servidores diferentes com intuito de concluir algum raciocínio pendente. O líder não respondia a questão gatilho.

Após esse período, todos os servidores mudaram de mesa, evitando ficar no mesmo grupo colaborativo na próxima mesa. Somente o líder ficou na mesa para a exposição oral das ideias geradas para o novo grupo de servidores recém-chegado. Feito essa exposição o líder nomeava um novo líder e participava da rotina, podendo responder a questão e obedecendo as mesmas regras anteriormente definidas. Essa rotina continuou até que todos 
os servidores visitaram todas as mesas de trabalho. Ao final aconteceram as apresentações com moderação do tutor de cada uma das folhas de flipchart (Fig. 3).

Figura 3: Uso da metodologia Jigsaw e atitude dialógica em prol da Educação Inclusiva

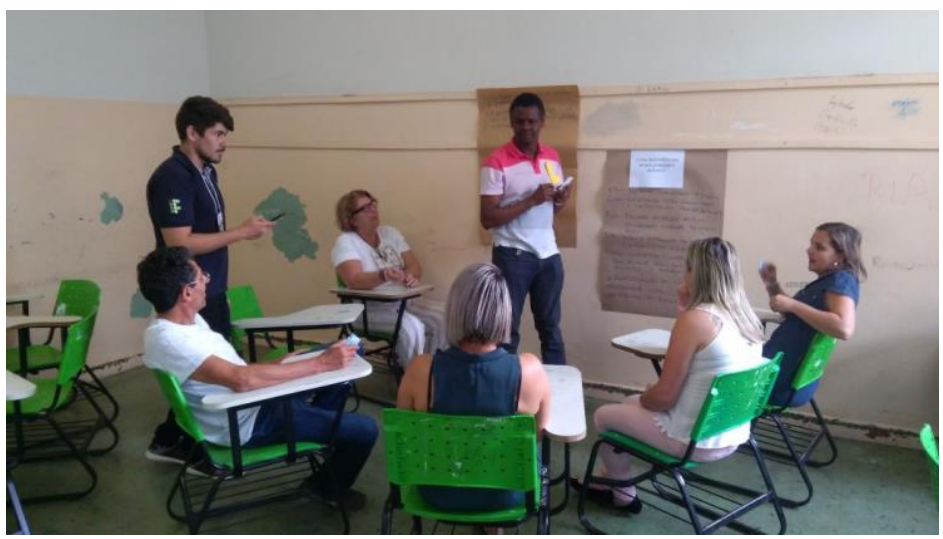

Fonte: Arquivo pessoal

\section{Objetivos da tarefa:}

- Exercícios de atitude dialógica;

- Proposição de respostas às perguntas deflagradoras;

- Pensar e planejar a Educação Inclusiva em grupo;

- Atitudes de Liderança.

\section{5) Metodologia Padlet com QR code para preenchimento do PLAC - Inclusão Digital}

(pano de fundo) (15:30-16:30): Após a rotina anterior, dentro da sala de aula foi oferecido o café da tarde, e enquanto os servidores ainda estavam se servindo, o tutor apresentou uma caixa de presente para os colegas, solicitando que eles verificassem do que se tratava. Algum servidor abriu a caixa de presente e apresentou seu conteúdo, o qual possuía um código QR e uma peça de quebra-cabeça (Fig. 4).

Após uma prévia discussão entre os servidores acerca do significado desses elementos, alguns servidores perceberam a necessidade de acessar o código QR usando seus dispositivos móveis (smartphones). De maneira interessante, alguns servidores desconheciam o que era o código e, intencionalmente foram "incluídos" digitalmente na plataforma Padlet associada ao QR.

RIAEE - Revista Ibero-Americana de Estudos em Educação, Araraquara, v. 13, n. esp1, p. 576-585, maio 2018. E-ISSN: $1982-5587$. 
Figura 4: Apresentação do código QR e do pedaço de quebra-cabeça dentro da caixa de

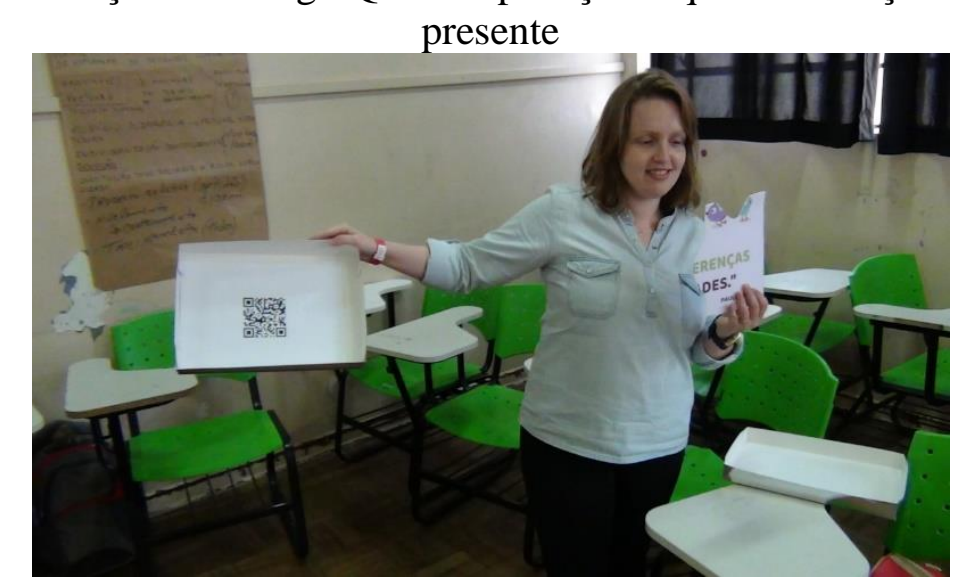

Fonte: Arquivo pessoal

A plataforma Padlet foi criada com intuito de promover o preenchimento do PLAC colaborativamente. Cada sala de aula possuía um código QR diferente, de tal maneira que cada sala de aula trabalhou com uma dimensão diferente do PLAC. Como o PLAC possuía oito dimensões, tivemos os resultados registrados nos links abaixo:

Dimensão 1: Gestão escolar

https://padlet.com/tatosouza2004/22ycuwl416f4

Dimensão 2: Prática pedagógica

https://padlet.com/tatosouza2004/uz6m9v687oej

Dimensão 3: Avaliação

https://padlet.com/tatosouza2004/cous4nl7hwcc

Dimensão 4: Acesso, permanência e sucesso na escola

https://padlet.com/tatosouza2004/zvc228mcfrne

Dimensão 5: Ambiente Educativo

https://padlet.com/tatosouza2004/nd9916lhfqom

Dimensão 6: Formação dos profissionais do campus (Docentes e Técnicos)

https://padlet.com/tatosouza2004/whngm7texutw

Dimensão 7: Relação Escola-Família

https://padlet.com/tatosouza2004/hrb0jimydcgy

Dimensão 8: Integração Escola-Trabalho

https://padlet.com/tatosouza2004/va8vscizct1c 
Para a construção colaborativa do documento, repetiu-se a metodologia Jigsaw previamente detalhada, mas considerando algumas pequenas adaptações: o líder foi o servidor que tinha o smartphone com o Padlet acessado; não havia o rigor do tempo do discurso, pois as ideias da atitude dialógica já haviam sido trabalhadas. Em cada rodada de discussão, a relação problema, ação, responsáveis e prazos de uma determinada dimensão é trabalhada.

\section{Objetivos da tarefa:}

- Exercícios de atitude dialógica já assimilados;

- Reflexões sobre deficiências, incluindo a digital;

- Desenvolvimento colaborativo e coletivo do PLAC-Produto Obrigatório;

- A surpresa como instrumento do estímulo à inclusão.

6) Encerramento (16:30-17:00): Feita toda a construção necessária, todos os servidores foram convidados a se encontrarem no auditório. Cada tutor com o seu pedaço de quebra-cabeça se apresenta no palco à frente de todos os servidores, e as peças são agrupadas montando o quebra-cabeça, o qual tinha uma citação de Paulo Freire: "A Inclusão acontece quando... se aprende com as diferenças e não com as igualdades”. É feito um pronunciamento de encerramento ilustrando o que representou a construção do quebra-cabeça e como toda essa rotina pedagógica, com seus respectivos objetivos, foram desenvolvidos. A reunião foi encerrada e cada servidor recebeu uma recordação do evento, sendo essa um embrulho contendo uma semente de girassol com um código QR remetendo à seguinte frase: "Seja a semente da inclusão".

\section{Objetivos da tarefa:}

- Revelando o porquê das coisas;

- Se ver no documento/processo como peça fundamental;

- Explorar orgulho em fazer parte.

\section{Considerações finais}

A construção de um PLAC acerca da Educação Inclusiva pode ser desafiador para qualquer instituição de ensino. Consideramos que pelo curto período de tempo, o avanço 
desse documento ainda inacabado foi fruto do emprego de metodologias ativas, trabalho colaborativo e muita confiança dos servidores no processo empregado. Ao final, perceber mesmo que subjetivamente o olhar de contentamento de grande parte dos servidores em reconhecer que cada um teve papel fundamental no documento implica em acreditar que é possível alterar algumas rotinas educacionais com uso das bem-sucedidas experiências finlandesas.

Agradecimentos: Os autores agradecem às colegas Daniela F. C. Cruvinel, Diana C. Abrão, Fabiana L. de Oliveira, Giovanna M. A. Carvas, Ieda M. S. Kawashita e Laura R. P. Pamplona por toda a contribuição na elaboração teórica e desenvolvimento prático de todas as ações apresentadas nesse artigo.

\section{REFERÊNCIAS}

BRANDÃO, Z. (Org). A crise dos paradigmas e a educação. 10 ed. São Paulo: Cortez. 2005.

MALLINEN, S.; PROKKI C. (Org). "Eu não sou um professor, sou um Educador" Finnish education meets Brazilian creativity. Tampere: Kirjapaino Hermes Oy. 2016.

\section{Como referenciar este relato de experiencia:}

DE SOUZA, Renato Aparecido.; SILVA, Grasiane Cristina da.; COIMBRA, Matheus Batista Barboza. Construção colaborativa de um plano de ação para a Educação Inclusiva: como a experiência educacional Finlandesa pode rechear esse processo? Revista IberoAmericana de Estudos em Educação, Araraquara, v. 13, n. esp1, p. 576-585, maio 2018. E-ISSN: 1982-5587. DOI: 10.21723/riaee.nesp1.v13.2018.11457

Submetido em: 30/10/2017

Aprovado em: 01/01/2018 